\title{
Abrupt climate change near the poles
}

\author{
Klaus Keller • Richard S. J. Tol • Ferenc L. Toth • \\ Gary W. Yohe
}

Received: 22 July 2008 / Accepted: 22 July 2008 / Published online: 10 September 2008

(C) The Author(s) 2008. This article is published with open access at Springerlink.com

Natura non facit saltus - but with anthropogenic climate change it just might. This is one of the major reasons for concern about greenhouse gas emissions. The North Atlantic Meridional Overturning Circulation (NAMOC)—widely but incorrectly known as the thermohaline circulation - and the West-Antarctic Ice Sheet (WAIS) are both poster children of this concern about extreme climate change scenarios, signifying the potential for regional cooling and rapid global sea level rise. Yet, both scenarios are uncertain in the Knightian sense. We know that the NAMOC has

K. Keller
Department of Geosciences, Pennsylvania State University,
University Park, PA, USA

R. S. J. Tol ( $\square)$

Economic and Social Research Institute,

Dublin, Ireland

e-mail: richard.tol@esri.ie

R. S. J. Tol

Institute for Environmental Studies,

Vrije Universiteit, Amsterdam, The Netherlands

R. S. J. Tol

Department of Spatial Economics, Vrije Universiteit,

Amsterdam, The Netherlands

R. S. J. Tol

Department of Engineering and Public Policy, Carnegie Mellon University,

Pittsburgh, PA, USA

F. L. Toth

International Institute for Applied Systems Analysis,

Laxenburg, Austria

G. W. Yohe

Department of Economics, Wesleyan University,

Middletown, CT, USA 
slowed down or even collapsed in the past and that the WAIS can disintegrate. We do not know, however, how likely these scenarios are, let alone how emission abatement would affect that probability. We know even less about the consequences, only that they may be serious. Uncertainty is, of course, no reason for inaction-indeed, uncertainty can substantially strengthen the case for emission reduction. However, uncertainty also opens possibilities for confusion, scaremongering, or denial.

This special issue contains eleven papers that (1) estimate or bound the probabilities and impacts of abrupt climate change and (2) analyze policy responses to such risks. This should allow for better informed decisions on climate policy. Three papers focus on the NAMOC, five papers are on the WAIS, and three papers are more generally about extreme climate scenarios. Four papers result from a workshop in Aspen funded by the US National Atmospheric and Oceanic Administration, and six papers from the Atlantis project, funded by the European Commission DG Research. The final paper was submitted to a generic issue of Climatic Change, but fits well within our theme.

Keller et al. (2008) provide an overview paper of a workshop on abrupt climate change hosted by the Aspen Global Change Institute in the summer of 2005. It outlines information needs and suggests research strategies for addressing them. It argues that the research agenda is becoming clear even though current understanding of potential climate change thresholds remains profoundly uncertain. This includes careful exploration of the fat tails of crucial parameters such as the climate sensitivity. Improving our estimates of the impacts associated with a growing list of possible thresholds and our estimates of how anthropogenic forcing affects their likelihoods will be crucial to enhancing our ability to select long-term policy objectives and to craft short-term hedges for the effective management of climate risk; and it is hedging that supports the claim that uncertainty is a reason to act.

Baehr et al. (2008) analyze the ability of a NAMOC monitoring system to provide timely detection of a weakening along three alternative SRES scenarios. This is a critical question in the hedging discussion-what should we monitor and how should we do it. They show that a 60 -year program provides $95 \%$ confidence of detecting changes of $1 \mathrm{~Sv}$ in the current's strength. The investment in such an NAMOC observation system would provide valuable information that can be used to improve climate change policies.

McInerney and Keller (2008) focus attention on a potential NAMOC collapse and use a stochastic version of Nordhaus' DICE model to derive economically efficient risk-reduction strategies. They show that a business-as-usual scenario results in a sizeable probability $(>10 \%)$ of triggering a NAMOC collapse within this century. Reducing this probability to less than $10 \%$ requires an almost complete decarbonization of the economy before 2100 — but this strategy does not maximize expected utility.

Vellinga and Wood (2008) use the HadCM3 model to explore the implications of a NAMOC collapse along an IS92A baseline. They show the northern hemisphere cooling by $1.7^{\circ} \mathrm{C}$ so that Europe returns to pre-industrial conditions with changes in precipitation generally pushing against the effects of warming except in western and southern Europe (where summer drying is enhanced) and in Central America and Southeast Asia (where projected reductions in precipitation are exaggerated). As a result, they see a potentially rapid reduction in the strength of the NAMOC 
increasing the range of projected climate uncertainty. Perhaps most significantly, Vellinga and Wood make it clear that specifying the baseline matters enormously.

Vaughan (2008) discusses the evolution in thinking about the West-Antarctic Ice Sheet, which has swung back and forth between concern about a potential collapse and reassurance that the ice sheet is fairly robust. In the popular media, this would be portrayed as battle between alarmists and deniers, but Vaughan is too level-headed to be drawn into that. Instead, the paper is a nice illustration of how new evidence leads to a revision of priors.

The papers from the Atlantis project study the impacts of a possible collapse of the West-Antarctic Ice Sheet from different angles. The methods adopted in this project include participatory integrated assessment techniques as well as cost-benefit and real options modelling. This methodological diversity indicates that policy insights for managing the risks of extreme climate change (large-scale singularities, to use the IPCC language) are likely to emerge from a range of approaches rather than from a single supermodel.

Toth and Hizsnyik (2008) start of with a discussion of the methods one may use for such an analysis. Before the start of the Atlantis project, it was decided that current impact models are unable to handle a non-marginal change like a collapse of the WAIS. Therefore, the impact estimates rely on expert knowledge. Toth and Hizsnyik describe the methods that were used to systematically elicit the collective knowledge of a group of expert stakeholders. These methods were applied in three case studies.

Olsthoorn et al. (2008) look at The Netherlands. They find that is technically and economically feasible to protect the country against a sea level rise of 5-6 m in a century. However, they argue that it is unlikely that there is sufficient political will at an early enough stage. If the start of the dike reinforcement programme is postponed until the first impacts are visible, it is too late and the country will need to be abandoned.

Lonsdale et al. (2008) also argue that retreat is the most likely option when London would be confronted with rapid sea level rise. Because of differences in geography, the extent of the retreat would be much less than in The Netherlands particularly if, as is likely, there would be a substantial upgrade of coastal protection as well. The authors also believe that some of the historical parts of London can be preserved in a "Venice of London", noting that the actual Venice is unlikely to survive.

Poumadere et al. (2008) study the Camargue, a nature reserve in the delta of the Rhone. Here as well, the likely decision is retreat although they argument is a different one. Whereas in the Thames estuary and the Rhine delta protection is infeasible or too expensive, in the Camargue it is undesirable: The choice is between losing a nature reserve to the sea or spoiling it with hard infrastructure. The authors also point to a remarkable degree of cultural adaptation, returning Mary Magdalena to the sea from where she came (but moving her shrine to higher grounds).

Nicholls et al. (2008) attempt to estimate the impact of a 5-m sea level rise using the DIVA database and the FUND model. They emphasize the adjustments that needed to made to the model-particularly, the replacement of linear with non-linear impact functions. The authors find that the impacts of a 5-m sea level rise are much worse than five times the impact of a 1-m sea level rise. They also note that the model predicts much higher levels of coastal protection than was found in the case studies of the Rhine, Rhone, and Thames. 
Guillerminet and Tol (2008) assess the implications for climate policy. Using different methods than previous studies in this field- specifically, real options implemented as dynamic programming - the authors confirm that low probability/high impact scenarios are a good reason to intensify and accelerate both mitigation and adaptation.

Open Access This article is distributed under the terms of the Creative Commons Attribution Noncommercial License which permits any noncommercial use, distribution, and reproduction in any medium, provided the original author(s) and source are credited.

\section{References}

Baehr J, Keller K, Marotzke J (2008) Detecting changes in the North Atlantic meridional overturning circulation based on an ocean observation array at $26 \mathrm{~N}$. Clim Change (this issue)

Guillerminet ML, Tol RSJ (2008) Decision making under catastrophic risk and learning: the case of the possible collapse of the West Antarctic Ice Sheet. Clim Change. doi:10.1007/s10584008-9447-4

Keller K, Yohe GW, Schlesinger ME (2008) Managing the risks of climate thresholds: uncertainties and information needs. Clim Change (this issue)

Lonsdale K, Downing TE, Nicholls RJ, Parker D, Vafeidis AT, Dawson R, Hall J (2008) Plausible responses to the threat of rapid sea-level rise for the Thames Estuary. Clim Change. doi:10.1007/ s10584-008-9483-0

McInerney D, Keller K (2008) What are reliable risk-management strategies in the face of uncertain climate thresholds? Clim Change (this issue)

Nicholls RJ, Tol RSJ, Vafeidis AT (2008) Global estimates of the impact of a collapse of the West Antarctic Ice Sheet: an application of FUND. Clim Change. doi:10.1007/s10584-008-9424-y

Olsthoorn AA, van der Werff PE, Bouwer L, Huitema D (2008) Neo-Atlantis: The Netherlands under a five meter sea level rise. Clim Change. doi:10.1007/s10584-008-9423-Z

Poumadere M, Mays C, Pfeifle G, Vafeidis AT (2008) Worst case scenario as stakeholder decision support: a 5-6 meter sea level rise in the Rhone Delta, France. Clim Change. doi: 10.1007/s10584-008-9446-5

Toth FL, Hizsnyik E (2008) Managing the inconceivable: participatory assessments of impacts and responses to extreme climate change. Clim Change. doi:10.1007/s10584-008-9425-x

Vaughan DG (2008) West Antarctic Ice Sheet collapse-the fall and rise of a paradigm. Clim Change. doi:10.1007/s10584-008-9448-3

Vellinga M, Wood R (2008) Impacts of thermohaline circulation shutdown in the twenty-first century. Clim Change (this issue) 